\title{
Through the Lens of Third Space Theory Possibilities for Research Methodologies in Educational Technologies
}

\author{
Kathy Jordan and Jennifer Elsden-Clifton \\ School of Education, RMIT University, Melbourne, Australia
}

Keywords: Educational Technologies, Third Space Theory, Research Methodology.

\begin{abstract}
Recently, there has been a call to reconceptualise the ways in which the field of education technology is researched and theorised (Graham, 2011). This article responds to this call, through discussing the potential of utilising Third Space theory as a research methodology in relation to the use, adoption and resistance to educational technologies. We begin by discussing the under-theorised and technocentric narrative that is dominant in current research approaches. We then outline the premise of Third Space theory and signal some of the possibilities this paradigm may offer to study the complexity of educational technology use in schools, professional learning and university contexts. The article then discusses findings from two different research projects which utilised Third Space to examine the ways in which beginning teachers and pre-service teachers navigated first and second space binaries and took up third spaces in order to destabilise and construct alternative knowledges and practices in relation to educational technology.
\end{abstract}

\section{INTRODUCTION}

The real voyage of discovery consists not in seeing new landscapes, but in having new eyes (Proust, cited in Canfield et al., 2002, p. 153).

With whose eyes were my eyes crafted? (Castor, 1991, cited in Davies, 1994, p. 18)

The methodology which a researcher employs has a number of implications for the scope of the study and the contribution of the research to the field. The methodology choice also orientates the values and beliefs that underpin the research and provides a lens to guide the researcher (Guba, 1990). For instance, the choice of methodology influences the lens in which the research is positioned and structured, the practices of the researcher (e.g. line of questioning) (Kuhn 1996) and the methods employed to conduct the research (Mertens, 2010). It can also determine the practicalities of the research - the who, why, what, where, when and how - and this will impact upon what is featured, highlighted, silenced and marginalised in the study. In this paper we argue that traditionally the methodology employed in educational technology research has led to technocentric and simplistic approaches to research; and the field has "learnt to see" educational technologies in particular ways, which we would argue can be limiting. In this paper we propose a move beyond a commitment to 'one truth, one method and one knowledge' and instead discuss ways to include more diverse ways of knowing, lenses for seeing and crafting research in this field (Grosz, 1994). To this end, we consider the potential that the theoretical paradigm Third Space can offer as a research methodology in the study of educational technology.

\section{EDUCATIONAL TECHNOLOGIES RESEARCH}

A key premise of Third Space theory is that everything is called into question (Hulme et al., 2009) and this includes taking up the challenge of integrating competing knowledge and challenging the binaristic thinking that has populated the research of educational technologies. The call to do so was highlighted in a recent paper in Computers \& Education, Charles Graham (2011) by way of leading into his focused discussion of the TPACK framework. He argued that one of the reasons for its popularity is because educational technology has been under theorised. He then went on to suggest a number of reasons for this apparent void in theory including the rapid pace of technological change, a tendency in the past to ask the wrong questions, weaknesses with methodological designs, and lastly, 
more priority being given to practical issues rather than on theory building. In this paper we wish to highlight some of the issues around methodological designs that have typically underpinned educational technology research as a way of advocating for alternate ways to do so.

In the past methodological designs in educational technology research have followed a similar pattern. At their heart has often been a world-view that implicitly assumes that technology is good, that for example, it is aligned with the future, and drives desired changes in education. One only has to peruse school education policy documents to find plenty of examples of this way of thinking, and where a technological road map that schools, school leaders and teachers should follow is provided, and where there is little capacity to consider detours or alternate routes. Underpinning this world-view is a techno-centric discourse, which places technology at the centre of the research if not the determining factor in it. This techno-centric discourse is the dominant discourse around educational technology research (Harris, 2005). It is important to note that dominant discourses, tend to subsume other less dominant ones (Gee, 1998), and as such, this may help explain why our educational technology field is under theorised.

In order to build a case for the research, or a justification for it, a problem in current practice is identified and a particular technological application is then later pitched as the solution (Bigum, 1998). Usually this case is made in overly enthusiastic terms, in what Selwyn (2002) refers to as the "technological evangelism" (p. 8) typifying this discourse. When building this case for the research, arguments usually take one or two forms. One way is to compare the 'new' to the 'old', with arguments around the superiority of the new, resulting in the conclusion, that the new technology must replace the old. Usually, there is little, if any consideration that both 'the old' and 'the new' can indeed co-exist. This has been the case historically, for example, in the 1980's revising writing was seen as time consuming (the old) and word processors (the new) were seen as making revising easier. In the 1990's conventional face-to-face participation in class discussion was seen as enfranchising those who think quickly on their feet. Electronic discussion was then juxtaposed, as enabling leaners to discuss when and where they want to.

A second way that the case is made is that particular affordances within a 'new' technology are identified as solutions to the problem (Zhao \& Rop 2001). This was the case in the 2000's, were web
2.0 technologies, such as blogs and wikis were readily positioned in research as enabling greater collaboration, interaction and knowledge building. The specific research questions then set out to prove that 'the new' or the 'affordances within the new' did in facto solve the problem. So for example in the late 1990's questions in hypertext research set out to examine how the new text structures afforded by this technology enabled the realisation of postmodern views of text - which were desired (Lankshear et al., 2000). Methods of data collection, particularly in the early years of educational technology research used anecdotal reports, or descriptions of practice. Findings were typically generalised, so that the particularities in the technologies being examined were overlooked, as well as the context of use. As a result, it was often assumed that all schools, all students, all teachers were the same and that predetermined technologically-enabled outcomes would be realised (Orlando, 2009).

Of concern to us is that without robust theoretical frameworks to both guide and shape research, that encourage us to assume diverse worldviews - with different questions in mind - techno-centric views will continue to underpin the landscape. Technocentric views only offer one lens with which to view our research, one that is based on binaries of good/bad, old/new, which limit alternate ways of conceptualising research. One theory which encourages this practice of looking at the complexity and multiplicity in educational technology is Third Space theory.

\section{POTENTIAL OF THIRD SPACE THEORY}

Third Space theory is essentially used to explore and understand the spaces 'in between' two or more discourses, conceptualizations or binaries (Bhabha, 1994). Soja (1996) explains this through a triad where Firstspace refers to the material spaces whereas Secondspace encompasses mental spaces (Danaher et al., 2003). Thirdspace, then becomes a space where "everything comes together" (Soja, 1996, p. 56, original emphasis) by bringing together Firstspace and Secondspace, but also by extending beyond these spaces to intermesh the binaries that characterise the spaces. Third Space theory is used as a methodology in a variety of disciplines and for different purposes. For example, it has been used to illustrate issues from colonization (Bhabha, 1994) and religion (Khan, 2000), to language and literacy 
(Gutiérrez et al., 1997).

Bhabha (1994) illustrated his conceptualization of Third Space through the discussion of cultural identity and colonization. Specifically, he explored the ways in which people negotiate being in-between their own traditional culture and the newly imposed culture; in other words being in-between first and second spaces. Bhabha (1994) argues that through a continual negotiation, reinterpretation and creation of identities, a hybrid or a third space which challenges both cultures is created. In illustrating the work of Bhabha - and drawing heavily from his explanation of Third Space - we are mindful that Bhabha's notion of Third Space is associated with the critique of colonization which does not directly relate to our research (Hulme, Cracknell \& Owens, 2009). However, aspects and foundations of his work are useful in our research around the utilisation of technologies in educational spaces.

Within educational contexts, Moje, et al. (2004) used Third Space theory to examine the in-between everyday literacies (home, community, peer group) with the literacies used within a schooling context. In their influential paper, they summarized the three main ways that theorists have conceptualised Third Space which includes: as a bridge; navigational space; and a transformative space of cultural, social, and epistemological change. To explain in more detail, the first way perceives third space as a bridge which according to Moje et al. (2004) helps learners see connections and contradictions and enables them to bridge competing and contradictory understanding. This concept was illustrated in Moje's et al. (2004) research into how students bridged inside and outside schooling literacies in the classroom and in doing so, created a space for typically marginalised voices or stories within their learning. When perceived as a navigational space, participants can cross over or draw upon different binaries, discourses or discursive boundaries. The other way that Third Space can be perceived is a transformative space, in which students' linguistic and cultural forms, goals, or ways of relating, transform the official space of the school, teacher, or classroom - enabling participants to become more central to their learning and gain access to alterative knowledges (Gutiérrez et al., 1999). This was evident in Elsden-Clifton's (2006) research into the visual arts created by migrant students, which found that students used their art to navigate between cultures and in doing so, negotiated being connected to, and 'in-between', different countries, cultures and spaces.

We have currently been involved in two recent research projects which have used a Third Space theory which we now turn to explain.

\subsection{Example 1: Beginning Teachers, Professional Learning and Educational Technologies}

The first research project used Third Space theory in a small-scale exploratory study that reported on ways in which 26 beginning teachers and an instructor, along with 3 online coaches and 2 moderators interacted in one Blackboard $(\mathrm{Bb})$ Collaborate session during a professional learning program. In the design and implementation of this research study, we were mindful of the dominant approaches that have been used in researching the introduction of new technologies. First, we wanted to move away from simplistic notions associated with the introduction of technology in learning (e.g. $\mathrm{Bb}$ Collaborate is a better method of instruction, when compared to older ways of instruction, or has particular affordances which should be used to remedy shortcomings or problems in instruction). Instead, we wanted our research to focus more on the complexities involved and acknowledge more critical views of technology introduction and use. In our quest we turned to the methodology of Third Space as it opens up difference spaces, allows for different presumptions around technology use by our research participants and ways of knowing our research site.

For this research study we associated conventional notions of face-to-face instruction with first space and the computer-mediated communication technologies, with second space. We identified three instances in an online interaction on $\mathrm{Bb}$ Collaborate between beginning teachers and instructors where the participants took up third spaces. We found that that beginning teachers were able to navigate, bridge and transform spaces and take up hybrid or third spaces. In particular, they disrupted the expert/novice binary by challenging the "teacher" and asking for and providing peer feedback rather than looking always to the expert. When in this third space, beginning teachers were able to take control of this space, shaping it to suit their own learning needs and destabilising the traditional roles of teacher/student. Thus, they were able to disrupt the traditions of first and second spaces and ultimately challenge who controls the interactions and the space. This research demonstrated some of the ways in which the theory may provide a way of recognizing the dynamic and maybe contradictorily spaces that educational 
technologies may take us.

\subsection{Example 2: Pre-Service Teachers using Educational Technology on Placement}

The second project investigated pre-service teachers' familiarity, confidence and perceived knowledge and skills of ICT implementation in the classroom during practicum. This research involved up to 70 pre-service teachers along with the School Principal and Teacher Mentors at their practicum school site. We were drawn to the Third Space construct as it enabled us to make visible the connections, and movement between binaries of pre-service teachers while on practicum in school (Bhabha, 1992). It provided a framework to acknowledge the tensions and dilemmas of pre-service teachers on placement as they struggled "to negotiate unfamiliar terrain" moving from their education application of technology (first space) and their personal knowledge of ICT use (second space).

Pre-service teachers while on placement inhabit a third space; they neither "belong" to the school, nor are they "at" university, thus, they are in-between these two spaces or in a third space. Through its emphasis on "between" we were able to research some of the struggles that pre-service teachers encountered as they interweaved the binaries of university/school, public/private, known/unknown, known/acquired and learner/teacher. It also provided a lens in which to examine the difficulties faced by pre-service teachers as they attempted to cross the boundaries of university based learning to learning to use technology in schools. The potential of third space for this research is that it did not see this dilemma or struggle as problematic or negative. Instead, Third Space methodology enabled us to draw attention to complexity around how pre-service teachers use technology while on placement and draw out the multiple possibilities and constraints of pre-service teachers' experiences of ICT while learning to teach.

\section{FINDINGS}

This paper has attempted to respond to the call for a continued conversation around the theoretical lens used to research educational technology. We believe that Third space has the potential to contribute to the field of educational technologies in three key ways, this includes:

- Provide a framework for destabilising and moving beyond the past patterns and stories of research in education technologies that encourage us to ask different research questions which consider alternate conceptualizations of uptake and use, rather than relying on binaries of $\mathrm{good} / \mathrm{bad}$, new/old, updated/outmoded, and valued/undervalued that have often characterized research

- Provide a research methodology that enable us to explore complexities in teacher use of technology

- Helping us to wrestle with the questions and complexities of education technology use in diverse contexts.

By proposing the use of Third Space theory within educational technology research, it is our hope that we contribute to an on-going conversation about the ways in which we research educational technologies. To this end, we feel it gives us possibilities to examine the complexities in education technology use and enables us to ask alternative research questions, that focus on the how and why of technologies within particular contexts rather than the what of technologies themselves. In doing so, it would also open up diverse research sites and take up potential opportunities to research more complex conceptualizations and move away from an overreliance on technocentric and binaristic conceptions of research.

\section{REFERENCES}

Bhabha, H. (1994). The location of culture. London: Routledge.

Bhabha, H. (1992). The third space: Interview with Homi Bhabha. In J. Rutherford (Ed.), Identity: community, culture, difference (pp. 207-221). London: Lawrence and Wishart.

Bigum, C. (1998). Boundaries, barriers and borders: Teaching science in a wired world. Australian Science Teachers Journal, 44(1), 13-24.

Canfield, J., Hanson, M., \& Zilkman, S. (2002). Chicken soup for the traveller's soul. Deerfield Beach, FL: Health Communication.

Davies, B. (1994). Poststructuralist theory and classroom practice. Geelong, VIC: Deakin University Press.

Danaher, P. A., Danaher, G. R., \& Moriarty, B. J. (2003). Space invaders and pedagogical innovators: Regional educational understandings from Australian occupational Travellers. Journal of Research in Rural Education, 18(3), 164-169.

Elsden-Clifton, J. (2006). Constructing 'Thirdspaces': Migrant students and the visual arts. Studies in Learning, Evaluation, Innovation and Development, 3(1), 1-11.

Gee, J. P. (1998). What is literacy? In V. Zamel \& R. 
Spack (Eds.), Negotiating academic literacies: Teaching and learning across languages and culture (pp. 51-59). Mahwah, NJ: Lawrence Erlbaum Associates.

Graham, C. R. (2011). Theoretical considerations for understanding technological pedagogical content knowledge (TPACK). Computers \& Education, 57(3), 1953-1960.

Grosz, E. (1994). Volatile bodies: Toward a corporeal feminism. St Leonards, NSW: Allen \& Unwin.

Guba, E. G. (Ed.). (1990). The paradigm dialog. Sage, Newbury Park, CA.

Gutiérrez, K. D., Baquedano-Lopez, P., Alvarez, H. H., \& Ming, C. M. (1999). Building a culture of collaboration through hybrid literacy practices. Theory Into Practice, 38(2), 87-93.

Gutiérrez, K.D., Baquedano-Lopez, P., \& Turner, M.G. (1997). Putting language back into language arts: When the radical middle meets the third space. Language Arts 75(5), 368-378.

Harris, J. (2005). Our agenda for technology integration: It's time to choose. Contemporary Issues in Technology and Teacher Education, 5(2). Retrieved from http://www.citejournal.org/vol5/iss2/editorial/ articlel.cfm. $\square$ AN $\square$ (2009). Learning in third spaces: Developing trans-professional understanding through practitioner enquiry. Educational Action Research, 17(4), 537-550.

Khan, S. (2000). Muslim Women: Crafting a North American identity. Gainesville: University Press of Florida.

Kuhn, T. S. (1996). The structure of scientific revolutions . Chicago: University of Chicago Press.

Lankshear, C., Snyder, I., \& Green, B. (2000). Teachers and techno-literacy. Managing literacy, technology and learning in schools. St Leonards, NSW: Allen and Unwin.

Mertens, D. M. (2010). Transformative mixed methods research. Qualitative Inquiry, 16(6), 469-474.

Moje, E., Ciechanowski, K., Kramer, K., Ellis, L., Carrillo, R., \& Collazo, T. (2004). Working toward third space in content area literacy: An examination of everyday funds of knowledge and discourse. Reading Research Quarterly, 39(1), 38-70.

Orlando, J. (2009). Understanding changes in teachers' ICT practices: A longitudinal perspective. Technology, Pedagogy and Education, 18(1), 33-44.

Selwyn, N. (2002). Telling tales on technology: Qualitative studies of technology and education. Hampshire: Ashgate Publishing Limited.

Soja, E. W. (1996). Thirdspace: Journeys to Los Angeles and other real and imagined places. Malden, MA: Blackwell.

Zhao, Y., \& Rop, S. (2001). A critical review of the literature on electronic networks as reflective discourse communities for inservice teachers. Education and Information Technologies, 6(2), 81-94. 